\title{
Greenhouse temperature control based on Fuzzy Logic
}

\section{Control de Temperatura para un Invernadero basado en Lógica Difusa}

ESQUIVEL-SALAS, Abraham†๋*, CASTAÑEDA-DELGADO, Jaime, SALAS-GUZMÁN, Manuel Ignacio and ARREDONDO-SALCEDO, Daniel

Instituto Tecnológico Superior Zacatecas Norte, Departamento deInformática y Sistemas Computacionales

ID $1^{\text {st }}$ Author: Abraham, Esquivel-Salas / ORC ID - 0000-0001-8258-8837, CVU CONACYT ID: 252850

ID $1^{\text {st }}$ Co-author: Jaime, Castañeda-Delgado / ORC ID: 0000-0001-9786-4128, CVU CONACYT ID: 252889

ID $2^{\text {nd }}$ Co-author: Manuel Ignacio, Salas-Guzmán / ORC ID: 0000-0002-7039-2703, CVU CONACYT ID: 316159

ID $3^{\text {rd }}$ Co-author: Daniel, Arredondo-Salcedo / ORC ID: 0000-0003-3236-4880, CVU CONACYT ID: 316030

DOI: $10.35429 /$ JCSI.2021.19.7.1.8

Received June 30, 2021; Accepted October 30, 2021

\begin{abstract}
There is a close relationship between crop growth and the control of environmental variables, as well as irrigation and fertilizers supplied. This article presents a system for collecting a greenhouse temperature, capable of acting in the opening or closing window system as a regulator of this environmental variable. Controlling the temperature acting on the opening or closing of the windows is convenient, since it does not require additional fuel, resulting in an economical alternative. Regarding control algorithm, Fuzzy Logic was used as a correction temperature technique. The proposal can be a good option for greenhouses that are not automated yet, saving costs by moving from humanassisted monitoring to automatic temperature monitoring.
\end{abstract}

Diffuse control, Temperature control, Protected agriculture

\begin{abstract}
Resumen
El crecimiento de los cultivos en sistemas de agricultura protegida está en función del control de las variables ambientales, así como por el riego y fertilizantes suministrados. En este artículo se presenta como propuesta un sistema para la recolección de temperatura de un invernadero, capaz de actuar en la apertura o cierre de las persianas como regulador de esa variable ambiental. Controlar la temperatura controlando la apertura o cierre de las ventanas resulta conveniente dado que no requiere combustibles, resultando en una alternativa económica. Respecto al control, se utilizó la Lógica Difusa como tecnica para la corrección de la temperatura. La propuesta puede resultar de interes para una gran cantidad de invernaderos que aún no están automatizados, ahorrando costos al pasar de una supervisión asistida por humanos a una supervisión de la temperatura automática.
\end{abstract}

Control difuso, Control de temperatura, Agricultura protegida

Citation: ESQUIVEL-SALAS, Abraham, CASTAÑEDA-DELGADO, Jaime, SALAS-GUZMÁN, Manuel Ignacio and ARREDONDO-SALCEDO, Daniel. Greenhouse temperature control based on Fuzzy Logic. Journal of Computational Systems and ICTs. 2021. 7-19:1-8

$\dagger$ Researcher contributing as first author. 


\section{Introduction}

The greenhouse crop growth depends on two aspects to be controlled, the environmental variables, as well as the amount of water and fertilizers supplied by irrigation. It is difficult to estimate production losses due to climate variability. There is a direct relationship between environmental variables control and the production, harvest, storage, transportation, even indirectly through diseases, pests, damage to infrastructure (Gommes, 1998).

A greenhouse is one of the best alternatives to controlling environmental variables. Proper climate control and fertigation in a closed environment results in optimal crop growth. However, the control of environmental variables and fertigation is also associated with increased costs related to energy, water and fertilizers (Rodríguez, Berenguel, Arahal, 2013).

From an economic perspective, the greenhouse aims to maximize production while minimizing its costs (Tap, Van Willigenburg, Van Straten, 1996; Rodríguez et al., 2003). The greenhouse environmental control can be carried out through ventilation and heating, modifying the temperature and humidity conditions, shading and artificial light to changing internal radiation, $\mathrm{CO}_{2}$ injection to photosynthesis influence and fogging to increase humidity.

Automated greenhouses generally focus their efforts on the control of natural ventilation, heating, and shading screens (Berenguel, Yebra, Rodríguez, 2003). Building greenhouses with technology to control environmental variables requires an investment that only few can do.

In the north of Zacatecas, it is possible to find non-automated greenhouses, that is, the care of the crop (temperature, irrigation) depends directly on the producer. In this research work we propose the development of a temperature control mechanism, which triggers the opening or closing of the blinds as a means of correcting, as far as possible, the temperature. The greenhouse temperature control system was developed using a fuzzy control based on the Mamdani architecture. In the next section, you will find a review of related research works, later, you will find a description of sensing temperature prototypes, as well as a control process description. Finally, conclusions and future work.

\section{State of art}

Due to the complexity represented by the development of a control system for environmental variables, based on heuristic rules obtained from producers experience, it is possible obtain from several studies, different techniques, advantages and disadvantages, in order to reach a solution (Galvan et al. 2012). In its classification, divides control systems into two main fields: conventional and optimal control. Conventional control consisting of theories that attempt to control the environment of a greenhouse, reducing the set points deviation between the interest variables and the measured values to zero.

On / Off, Proportional Integral Derivative Controller (PID) and some Artificial Intelligence paradigms such as Artificial Neural Networks (ANN), Fuzzy Logic-based Systems (FLS), Genetic Agorithms ( GA), among others, can be conventional control examples.

On the other hand, in Optimal Control, aspects such as greenhouse behavior, actuator capacities, energy consumption and mainly the crop response are considered as input parameters of the control process. Expert systems and the Predictive Control Model (MPC) are some of the most common techniques. However, Artificial Intelligence based techniques can also be considered as an optimal control when considering the crop response as input parameter.

Systems based on Fuzzy Logic control have achieved important results in greenhouses temperature control field. For this, it is necessary to have reliable information about system behavior, as well as a correct abstraction to create rules based on heuristic and empirical knowledge from the producer's experience. In addition, fuzzy control can be robust and cheap (Passino, Yurkovich, Reinfrank, 1998).Castañeda, Ventura, Peniche y Herrera (2006), propose an interesting Fuzzy Logic application to controlling climiatic variables, using an FPGA to execute low-level tasks, such as the monitoring of climatic variables and the operation of actuators, like heaters and windows to control the internal greenhouse temperature. His project uses a data acquisition module, one analog/digital conversion module, and a third fuzzy logic FPGA module. 
Gómez et al. (2011) presents fuzzy control proposal over FPGA for greenhouse fertigation control. This project presents the modularization of its system, emphasizing the potential to save significant amounts of water and nutrients compared to conventional systems, as a product of diffuse control. Additionally, they emphasize some characteristics of fuzzy control, mainly its adaptability, simplicity, and ease of implementation, making it an excellent tool for its application in the optimization of fertigation systems.

Finally, more studies can be found in the literature that present advantages of Fuzzy Control over traditional control systems in greenhouse automation (Ödük y Allahverdi, 2012).

\section{Sensorization}

The design and conditioning of a prototype was made for the automation of a greenhouse with the Intel Galileo and Arduino microcontroller. The first prototype is the automatic control of opening and closing of greenhouse windows that is carried out through a $24 \mathrm{~V}, 500 \mathrm{~W}, 1800 \mathrm{RP}$ motor that was implemented with the PWM (SHT-146), which is a reversible control and of speeding for $6 \mathrm{~V}-30 \mathrm{~V}, 6 \mathrm{~A}$ motors (see figure 1).

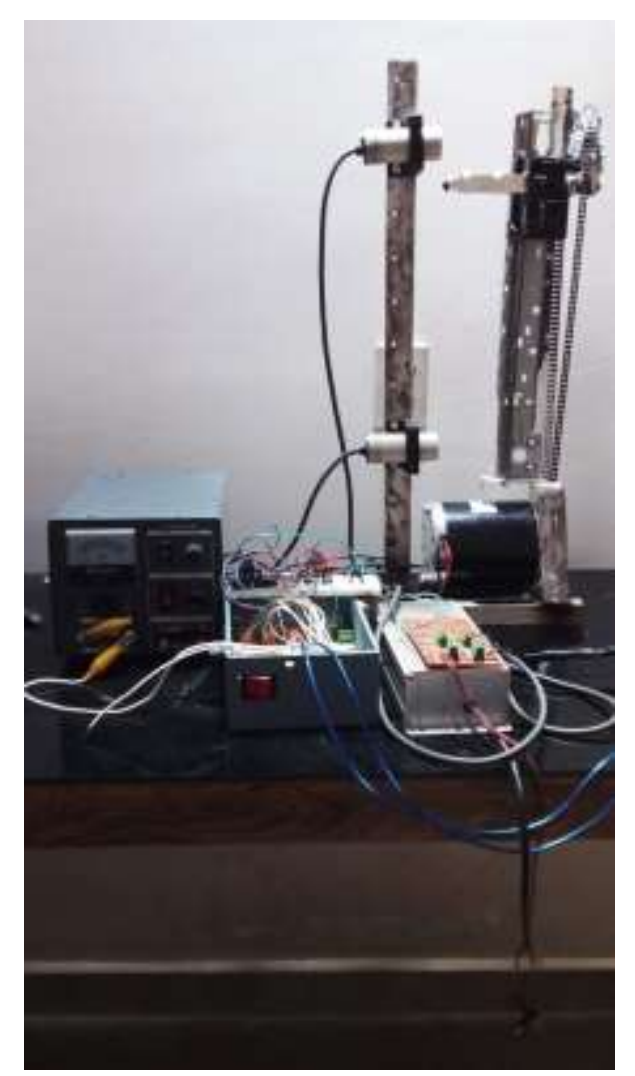

Figure 1 Motor, automatic control prototype, and capacitive proximity sensors.
The second prototype consists in the conditioning and install of two capacitive proximity sensors (E2K-C25MF1) strategically located for detect the closing and total opening greenhouse windows. These prototypes keep a Wireless communication trough Xbee with a relative humidity and temperature probe (HMP60-Vaisala) located in the center of the greenhouse, for monitoring and optimize the relative humidity of the environment. The sensorization for the shutter opening and closing control, as well as the humidity and relative temperature control of the greenhouse, is energized with a solar charge control (EPRC$12 / 24 \mathrm{~V}$ 10Amp) for efficient energy consumption. It was developed a sensorization module that consist in two parts:

\section{Transmitter}

A first transmitter module, that consist in an Arduino Uno microcontroller, initially equipped of a temperature sensor Keyes DS18B20, responsible for acquiring the temperature, recording any variation in the greenhouse (see figure 2). Also, a Xbee microcontroller was installed, which provided the module with Wireless communication, in such a way that when temperature changes are registered, they are sent to a second receiver module.

The wireless communication provided by the XBee was a restriction given the distance from the center of the greenhouse to the corners, which is where the manual mechanisms for opening-closing the windows are located. The energy supply of this transmitter module is in charge of a solar cell.

Vaisala HMP60 probe calibration. The probe sends voltage as a product of the temperature and humidity reading. The algorithm was developed to convert the values expressed in voltage by the probe to temperature. The readings obtained from the Keyes DS18B20 sensor, Vaisala probe and an analog thermometer were verified, with a difference of less than half a degree centigrade between the three readings. Once the input was verified, the Keyes DS18B20 sensor used for prototyping was replaced by the Vaisala probe, for industrial use (see Figure 3). 


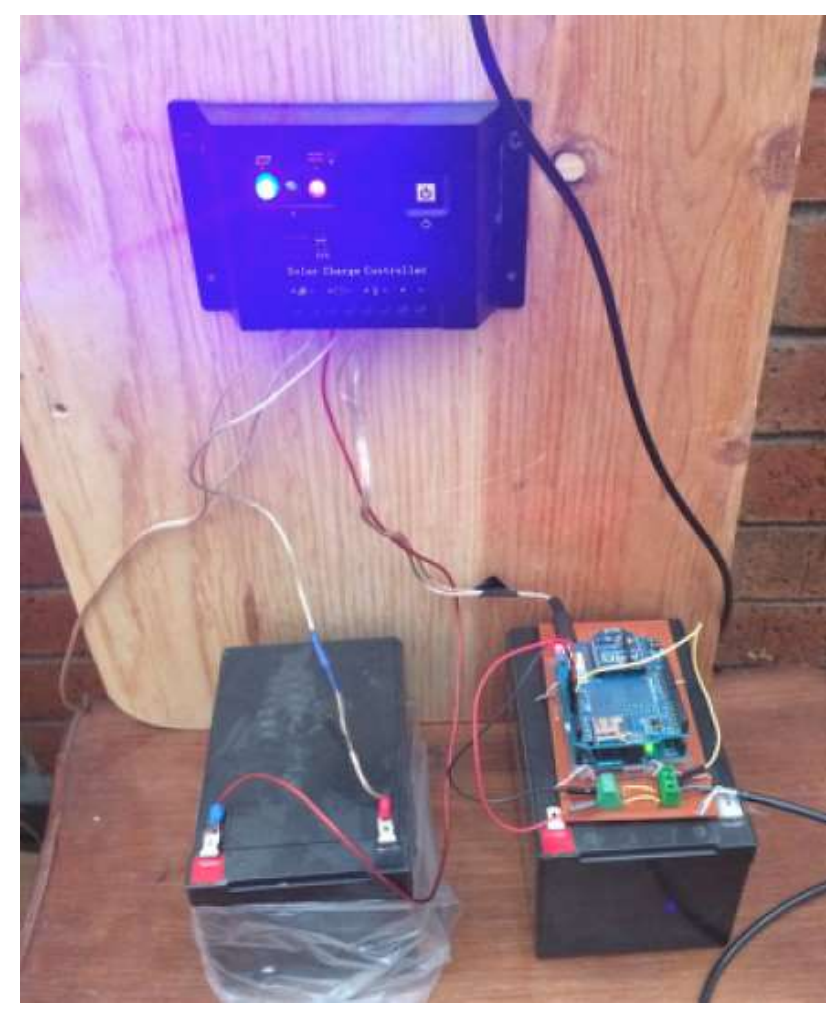

Figure 2 Transmitter. Notice an Arduino Uno microcontroller, powered by power from a solar cell. See the cable that goes up, corresponding to the Vaisala probe, which does the temperature measurement

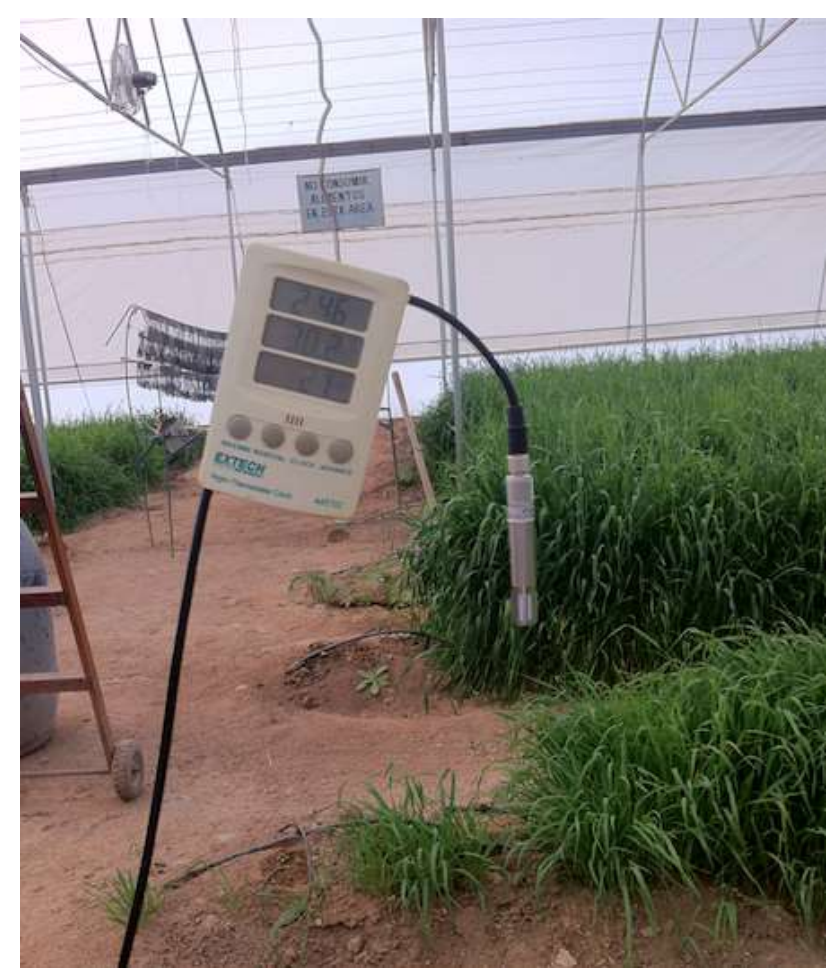

Figure 3 Vaisala probe calibration with respect to the thermometer they have in the greenhouse.

\section{Receiver}

The receiver is integrated by a Galileo Generation 2 microcontroller with Yocto operating system, the temperature readings arrive remotely through an Xbee microcontroller (see figure 4).
Limits configuring. The Galileo microcontroller has a web server and some scripts developed in Python, which allow you to configure the temperature limits from a web application. Lower limit defines the minimum allowable temperature in which the plant can be without stress.

\section{temperature}

Upper limit defines the maximum

Ideal, defines the optimum temperature for the type of crop.

The objective of the limits is to control the opening and closing of the windows, according to the temperature readings that arrive. An austere diffuse temperature controller will be in charge of making the temperature as close as possible to the ideal temperature. Basically, as you get closer to the maximum and minimum limits, the temperature correction will be more frequent.

The windows have sensors that allow to know if the window is completely open or completely closed, in which case, the motor no longer operates the window only in that sense.

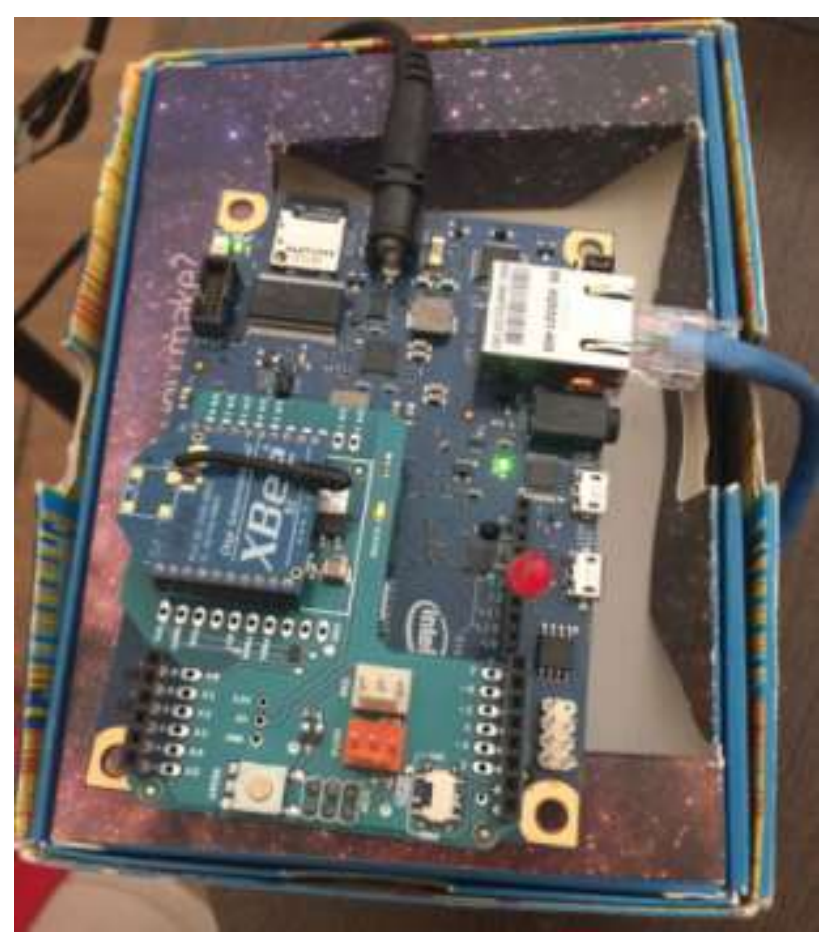

Figure 4 Galileo receiver. The ethernet interface sends the measurements to a remote server 


\section{Control design}

The blinds' control is a control system based on fuzzy logic and is conformed by a closed loop controller of the Proportional-Derivative type, with two inputs and one output. The physical inputs of the system are the ideal temperature and the current temperature, concerning of the inference machine, the inputs are the error and the derivative of the error. As a result, the inference machine generates the opening percentage that the blinds will have. The fuzzy inference machine is made up of three essential parts: Diffusion, Reasoning or IF-THEN Fuzzy Rules and defuzzification.

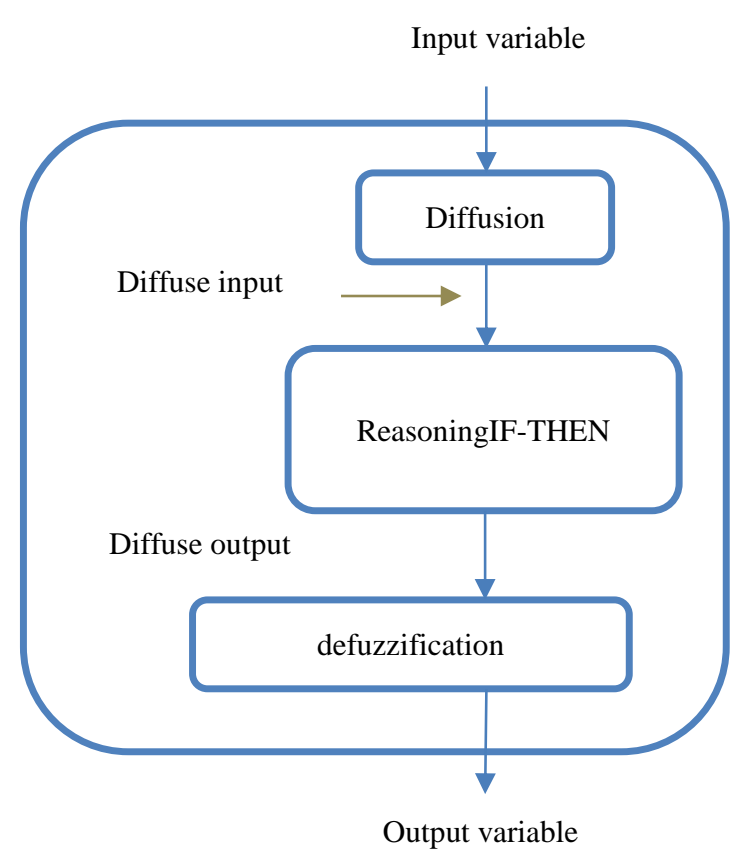

Figure 5 Fuzzy inference machine

Diffusion is a process in which physical variables are converted into fuzzy inputs, the value of the variables is evaluated, and they are assigned a degree of membership in the fuzzy sets defined by the designer. To carry out this process, the membership functions of fuzzy sets are used.

The reasoning within a fuzzy inference machine is responsible for evaluating the rules proposed by the designer. The rules relate the fuzzy inputs and generate the fuzzy output; These rules are called "Fuzzy Rules" later this fuzzy output is converted into a real output through the de-diffusion process, with the real output the system will perform the desired action.

\section{Mamdani's inference machine}

For this project the Mamdani inference was used (Lee, 1990; Tamir, Rishe, Kandel, 2015).

Mamdani's fuzzy rules:

$$
\text { IF ( } X_{1} \text { is A AND } X_{2} \text { is B) THEN ( } U_{1} \text { is } C \text { ) }
$$

Where $X_{1}$ y $X_{2}$ are the input variables, $A$ y $B$ are the membership functions input, $U_{l}$ is the fuzzy output and $C$ is the output membership function. The first part of the statement " $I F$ ( $X_{I}$ is A AND $X_{2}$ is $B$ )" is known as antecedent and $\operatorname{THEN}\left(U_{I}\right.$ is $C$ ) is the consequent.

As advantages it can be determined that it is intuitive, widely accepted, adapted to the incorporation of knowledge and experience. Defuzzification is the conversion of the diffuse output of the inference machine to an output variable, that is, the result obtained from the rules within the inference machine will be translated into a real physical signal for our control system.

For defuzzification there are several methods, it is important to choose the right one.

\section{a) Centroid method}

The Center of Gravity or Center of Area method is the most used of the defuzzification methods and its expression is as follows:

$$
Z^{*}=\frac{\int \mu(u) * u i d c}{\int \mu(u i) d c}
$$

Where $\int$ is the algebraic integral; $u i$ is the typical value of each function and $\mu(u i)$ is the membership value in this function. For this method, it is necessary to use a microcontroller that performs the most accurate and efficient calculations since the formula contains integrals, so the processing time would increase. So it is more expensive.

\section{b) Center of Maximum Method (COM)}

In this method, the fuzzy set of the output variable and its membership values are considered, such that the sum of the membership values is equal to one, $\sum \mu(u i)=1$, where $u i$ are the typical values of each membership function that are part of the output set. The membership values are weighted with the typical values of each function.

ESQUIVEL-SALAS, Abraham, CASTAÑEDA-DELGADO, Jaime, SALAS-GUZMÁN, Manuel Ignacio and ARREDONDO-SALCEDO, Daniel. Greenhouse temperature control based on Fuzzy Logic. Journal of Computational Systems and ICTs. 2021 
The actual output is obtained with the expression:

$Z^{*}=\frac{\sum_{i=1}^{n} \mu(u i) * \mathfrak{u i}}{\sum_{i=1}^{n} \mu(u i)}$

Where $u i$ is the typical value of each function. $\mu(u i)$ is the membership value in this function.

The COM it is an efficient method, if symmetric functions are used, also it can obtain real output values using limited computational resources. This method was used in this project because of its low cost.

Input

Regarding the controller, its inputs are given by the temperature error obtained from the greenhouse temperature. (Ideal temperature Current temperature) and the Derivative of the temperature error $(d E / d t)$, which is the difference between the current error and the previous one.

The fuzzy inputs, composed of the Temperature Error and the Temperature Derivative, they are processing with a diffusion process, assigning membership values. With a range of 20 to 44 degrees, a Lambda function, three triangular functions, and a gamma were defined.

Very Positive (MP) Lambda

$L(u ; 20,26)\left\{\begin{array}{l}1, \text { if } u \leq 20 ; \\ \frac{26-u}{26-20} \\ 0, \text { if } u>26 .\end{array}\right.$, si $20 \leq u \leq 26 ;$

Positive (P) Triangular

$\Lambda(u ; 20,26,32)\left\{\begin{array}{c}0, \text { if } u \leq 20 ; \\ \frac{u-20}{26-20}, \text { if } 20 \leq u \leq 26 ; \\ \frac{32-u}{32-26}, \text { if } 26 \leq u \leq 32 ; \\ 0, \text { if } u>32 .\end{array}\right.$

Zero (Z) Triangular

$\Lambda(u ; 26,32,38)\left\{\begin{array}{c}0, \text { if } u \leq 26 ; \\ \frac{u-26}{32-26}, \text { if } 26 \leq u \leq 32 ; \\ \frac{38-u}{38-32}, \text { if } 32 \leq u \leq 38 ; \\ 0, \text { if } u>38 .\end{array}\right.$
Negative (N) Triangular

$\Lambda(u ; 32,38,44)\left\{\begin{array}{c}0, \text { if } u \leq 32 ; \\ \frac{u-32}{38-32}, \text { if } 32 \leq u \leq 38 ; \\ \frac{44-u}{44-38}, \text { if } 32 \leq u \leq 44 ; \\ 0, \text { if } u>44 .\end{array}\right.$

\section{Very Negative (MN) Gamma}

$\Gamma(u ; 38,44)\left\{\begin{array}{l}0, \text { if } u \leq 38 ; \\ \frac{u-38}{44-38} \\ 1, \text { if } u>44 .\end{array}\right.$, if $38 \leq u \leq 44 ;$

The Error's derivative has a range between -1 to 1 , where -1 indicates that the greenhouse temperature is cold compared to the ideal temperature, therefore, the blinds must remain closed. On the contrary, 1 indicates that the temperature has risen, so the blinds must be open.

Negative Derivative (DN) Lambda Function

$L(u ;-1,-0.5)\left\{\begin{array}{l}1, \text { if } u \leq-1 ; \\ \frac{-0.5-u}{-0.5+1}, \text { if }-1 \leq \\ 0, \text { if } u>-0.5 .\end{array}\right.$

Low Negative Derivative (PND) Triangular Function

$\Lambda(u ;-1,-0.5,0)\left\{\begin{array}{c}0, \text { if } u \leq-1 ; \\ \frac{u+1}{-0.5+1}, \text { if }-1 \leq u \leq-0.5 \\ \frac{0-u}{0+0.5}, \text { if }-0.5 \leq u \leq 0 \\ 0, \text { if } u>0 .\end{array}\right.$

Zero Derivative (DC) Triangular Function

$\Lambda(u ;-0.5,0,0.5)\left\{\begin{array}{c}0, \text { if } u<-0.5 ; \\ \frac{u+0.5}{0+0.5}, \text { if }-0.5 \leq u \leq 0 ; \\ \frac{0.5-u}{0.5-0}, \text { if } 0 \leq u \leq 0.5 ; \\ 0, \text { if } u>0.5 .\end{array}\right.$

Low Positive Derivative (DPP) Triangular Function

$\Lambda(u ; 0,0.5,1)\left\{\begin{array}{c}0, \text { if } u<0 ; \\ \frac{u-0}{0.5-0}, \text { if } 0 \leq u \leq 0.5 ; \\ \frac{1-u}{1-0.5}, \text { if } 0.5 \leq u \leq 1 ; \\ 0, \text { if } u>1 .\end{array}\right.$

ESQUIVEL-SALAS, Abraham, CASTAÑEDA-DELGADO, Jaime, SALAS-GUZMÁN, Manuel Ignacio and ARREDONDO-SALCEDO, Daniel. Greenhouse temperature control based on Fuzzy Logic. Journal of Computational Systems and ICTs. 2021 
Positive Derivative (PD) Gamma Function

$\Gamma(u ; 0.5,1)\left\{\begin{array}{c}0, \text { if } u<0.5 ; \\ \frac{u-0.5}{1-0.5}, \text { if } 0.5 \leq u \leq 1 \\ 1, \text { if } u>1 .\end{array}\right.$

The fuzzy rules from Mamdani's architecture, generated from the field experience that the inference machine follows, can be seen in a fuzzy memory.

\begin{tabular}{|c|c|c|c|c|c|c|}
\hline \multicolumn{5}{|c|}{ Temperature error } & & \multirow{7}{*}{ 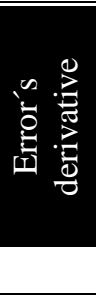 } \\
\hline $\mathrm{MN}$ & $\mathrm{N}$ & $\mathrm{C}$ & $\mathrm{P}$ & MP & & \\
\hline A & $\mathrm{AB}$ & $\mathrm{C}$ & $\mathrm{CB}$ & $\mathrm{C}$ & DN & \\
\hline $\mathrm{A}$ & $\mathrm{AB}$ & $\mathrm{CA}$ & $\mathrm{CB}$ & $\mathrm{C}$ & DPN & \\
\hline A & $\mathrm{AA}$ & $\mathrm{N}$ & $\mathrm{CA}$ & $\mathrm{C}$ & $\mathrm{DC}$ & \\
\hline $\mathrm{A}$ & $\mathrm{AB}$ & AA & $\mathrm{CB}$ & $\mathrm{C}$ & DPP & \\
\hline A & $\mathrm{AB}$ & $\mathrm{A}$ & CB & $\mathrm{C}$ & DP & \\
\hline \multicolumn{6}{|c|}{ Expected output } & \\
\hline
\end{tabular}

Table 1 Fuzzy memory

The defuzzification of the output can be presented in figure 6 .

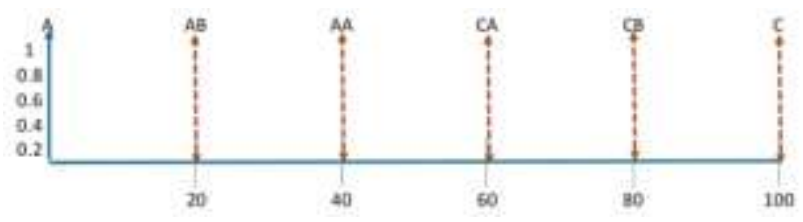

Figure 6 Output of the Fuzzy Control, percentage of opening / closing of blinds

Open $=\mu(\mathrm{u})=\left\{\begin{array}{l}1, \text { if } u=0 \\ 0, \text { if } u \neq 0\end{array}\right.$

Low open $=\mu(\mathrm{u})=\left\{\begin{array}{l}1, \text { if } u=20 \\ 0, \text { if } u \neq 20\end{array}\right.$

High open $=\mu(\mathrm{u})=\left\{\begin{array}{l}1, \text { if } u=40 \\ 0, \text { if } u \neq 40\end{array}\right.$

High close $=\mu(\mathrm{u})=\left\{\begin{array}{l}1, \text { if } u=60 \\ 0, \text { if } u \neq 60\end{array}\right.$

Low close $=\mu(\mathrm{u})=\left\{\begin{array}{l}1, \text { if } u=80 \\ 0, \text { if } u \neq 80\end{array}\right.$

Close $=\mu(\mathrm{u})=\left\{\begin{array}{l}1, \text { if } u=100 \\ 0, \text { if } u \neq 100\end{array}\right.$

Applying the COM method for inverse diffusion, starting from the maximums of the Error Derivative and the Temperature Error

\section{Results}

The control has been tested in a mechanical prototype (see figure 1), where the opening / closing has been checked according to the percentage generated by the control with Fuzzy Logic.

\section{Acknowledgment}

This research project was made possible thanks to the sponsorship of Instituto Tecnológico Superior Zacatecas Norte.

\section{Conclusions}

The fuzzy control laboratory tests are satisfactory when controlling the opening / closing of the blinds, thus affecting the temperature.

This technological solution provides an automatic temperature control, reducing costs and working time. In non-automated greenhouses, a person must be controlling the environmental variables all time.

\section{References}

Berenguel, M., Yebra, L. J., \& Rodríguez, F. (2003). Adaptive control strategies for greenhouse temperature control. In 2003 European Control Conference (ECC) (pp. 27472752). IEEE.

Castañeda-Miranda, R., Ventura-Ramos Jr, E., del Rocío Peniche-Vera, R., \& Herrera-Ruiz, G. (2006). Fuzzy greenhouse climate control system based on a field programmable gate array. Biosystems engineering, 94(2), 165-177.

Galvan, C. D., Pacheco, I. T., González, R. G. G., de Jesus Romero-Troncoso, R., Medina, L. C., Alcaraz, M. R., \& Almaraz, J. M. (2012). Advantages and disadvantages of control theories applied in greenhouse climate control systems. Spanish Journal of Agricultural Research, (4), 926-938.

Gómez-Melendez, D., Lopez-Lambrantilde, A., Herrera-Ruiz, G., Fuentes, C., Rico-Garcia, E., Olvera-Olvera, C., ... \& Verlinden, S. (2011). Fuzzy irrigation greenhouse control system based on a field programmable gate array. 
Gommes, R. (1998). Climate-related risk in agriculture. In IPCC Expert Meeting on Risk Management Methods (p. 13). AES, Environment Canada.

Lee, C. C. (1990). Fuzzy logic in control systems: fuzzy logic controller. I. IEEE Transactions on systems, man, and cybernetics, 20(2), 404-418.

Ödük, M. N., \& Allahverdi, N. (2012). The advantages of fuzzy control over traditional control system in greenhouse automation. ICGST-AIML-11 conference, Dubai, UAE.

Passino, K. M., Yurkovich, S., \& Reinfrank, M. (1998). Fuzzy control (Vol. 42, pp. 15-21). Reading, MA: Addison-wesley.

Rodríguez, F., Berenguel, M., \& Arahal, M. R. (2003). A hierarchical control system for maximizing profit in greenhouse crop production. In 2003 European Control Conference (ECC) (pp. 2753-2758). IEEE.

Tamir, D. E., Rishe, N. D., \& Kandel, A. (Eds.). (2015). Fifty years of fuzzy logic and its applications (Vol. 326). Springer.

Tap, R. F., Van Willigenburg, L. G., \& Van Straten, G. (1996). Receding horizon optimal control of greenhouse climate based on the lazy man weather prediction. IFAC Proceedings Volumes, 29(1), 889-894. 